\title{
Solitary Asymptomatic Thyroid Metastasis from Hepatocellular Carcinoma Detected by FDG-PET/CT
}

\author{
Takeo Toshima $^{\mathrm{a}} \quad$ Akinobu Taketomi $^{\mathrm{a}}$ Ken Shirabe $^{\mathrm{a}}$ \\ Kazuki Takeishia Takashi Motomura ${ }^{a}$ Youhei Mano ${ }^{a}$ \\ Kazutoyo Morita ${ }^{a}$ Takasuke Fukuhara $^{a}$ Keishi Sugimachi ${ }^{a}$ \\ Yasuhiro Maruoka ${ }^{b}$ Koichiro Abe ${ }^{b}$ Tsuyoshi Tajima $^{b}$ \\ Yoshihiko Maehara ${ }^{a}$ \\ aDepartment of Surgery and Science and bepartment of Clinical Radiology, \\ Graduate School of Medical Sciences, Kyushu University, Fukuoka, Japan
}

\section{Key Words}

Thyroid metastasis · Hepatocellular carcinoma · FDG-PET/CT

\begin{abstract}
Thyroid metastases from hepatocellular carcinoma (HCC) seldom occur and are often difficult to diagnose because of their asymptomatic clinical course. We evaluated a very rare case of solitary thyroid metastasis from HCC that showed high uptake of fluorine-18 fluorodeoxyglucose (FDG), when imaged using fluorine-18 fluorodeoxyglucose positron emission tomography/computed tomography (FDG-PET/CT). The patient was a 74-year-old man and presented with a remarkably elevated des-gamma-carboxy prothrombin level of $1,157 \mathrm{mAU} / \mathrm{ml} 22$ months after hepatic lobectomy. FDG-PET/CT imaging revealed a hypodense tumor with high FDG uptake, with a maximum standardized uptake value of 5.2 in the thyroid left lobe. Solitary thyroid metastasis from $\mathrm{HCC}$ was suspected and subsequent fine needle aspiration did indeed reveal HCC. The patient received left thyroidectomy with left regional lymph node dissection. Two months after left thyroidectomy, contrast-enhanced computed tomography showed local recurrence, and the patient received ongoing radiotherapy treatment. To our knowledge, the present study is the first to demonstrate the feasibility of FDG-PET/CT in the diagnosis and management of clinically diagnosed, asymptomatic, solitary thyroid metastasis from HCC.
\end{abstract}




\section{Introduction}

Hepatocellular carcinoma (HCC) is one of the most common cancers in the world. Various treatments are available such as hepatectomy, liver transplantation, transcatheter arterial chemoembolization and systemic chemotherapy. However, after the completion of treatment some patients present with intra- and extrahepatic metastasis [1,2]. It is relatively easy to diagnose bone metastasis due to the symptom of pain, but with lung and adrenal gland metastasis there are often no symptoms, making diagnosis more difficult [3]. If extrahepatic metastasis from HCC is diagnosed, the stage is designated as stage IV (according to the 6th edition of the AJCC Cancer Staging Manual) [4], prognosis is poor and the treatment strategy changes dramatically [1-3]. Therefore, it is considered that early and precise diagnosis of extrahepatic metastasis from HCC is very important for optimal treatment $[2,3]$. As far as we are aware, the present study is the first to evaluate the feasibility of fluorine-18 fluorodeoxyglucose positron emission tomography/ computed tomography (FDG-PET/CT) in the diagnosis and management of clinically diagnosed, asymptomatic, solitary thyroid metastasis from HCC.

\section{Case Report}

After a health checkup, a 74-year-old man without any symptoms was admitted for treatment due to an abdominal abnormality detected using ultrasound. His past medical history was unremarkable. The patient's general health status was good and physical examination did not reveal anemia, jaundice or an abdominal or thyroid mass. Laboratory data were normal: hemoglobin level $12.0 \mathrm{~g} / \mathrm{dl}$, platelet count $14.3 \times 10^{4} / \mathrm{mm}^{3}$, albumin $3.4 \mathrm{~g} / \mathrm{dl}$, total bilirubin $0.7 \mathrm{mg} / \mathrm{dl}$, aspartate aminotransferase $38 \mathrm{IU} / \mathrm{l}$, alanine aminotransferase $17 \mathrm{IU} / \mathrm{l}$, alkaline phosphatase $188 \mathrm{IU} / \mathrm{l}$, gamma-glutamyltranspeptidase $26 \mathrm{IU} / \mathrm{l}$, lactate dehydrogenase $164 \mathrm{IU} / \mathrm{l}$; and creatinine level $0.83 \mathrm{mg} / \mathrm{dl}$. Tests for the hepatitis B virus antigen and anti-hepatitis $\mathrm{C}$ virus antibody were negative. Contrast-enhanced abdominal computed tomography (CT) revealed heterogeneously enhanced lesions in the liver. The largest mass was roughly $6.0 \times 5.5 \mathrm{~cm}$ $(\mathrm{S} 3 / 4 / 1)$. A small $3 \mathrm{~mm}$ mass in the right lobe (S5) was suspected as being intrahepatic metastasis. Serum des-gamma-carboxy prothrombin was high at a level of 2,157 $\mathrm{mAU} / \mathrm{ml}$ relative to the normal level of $<40 \mathrm{mAU} / \mathrm{ml}$. However, serum alpha fetoprotein was normal at a level of $4.1 \mathrm{ng} / \mathrm{ml}$ relative to the normal level of $<6.2 \mathrm{ng} / \mathrm{ml}$.

Three weeks after the initial diagnosis, transcatheter arterial embolization (TAE) and chemo-lipiodolization (LPD) were performed prior to hepatectomy. This procedure was carried out because intrahepatic metastasis was suspected in the right lobe and because there was a possibility that the likelihood of postoperative recurrence might be decreased due to the adoption of this treatment strategy, such as has been found to be the case after hepatectomy of HCC following TAE [5]. Extended left lobectomy of the liver was performed 2 months after diagnosis because HCC was not completely eradicated by TAE and LPD treatment. Excision of the remaining mass revealed a well-defined, tan-white, firm tumor measuring $5.3 \times 5.1 \times 4.3 \mathrm{~cm}$, with submassive necrosis and hemorrhage (fig. 1a). Histological analysis revealed a moderately to poorly differentiated HCC. Microscopically, the tumor could be seen directly invading the liver capsule. The surgical margin was $1 \mathrm{~mm}$ from the tumor and under microscopic analysis appeared negative for tumor cells. The tumor featured cells growing in trabecular and compact patterns (fig. 1b). Tumor invasion of the distal portal vein and distal vein was evident. No liver cirrhosis was noted. After complete pathological examination, the patient's pTNM stage was pT3N0M0 (solitary tumor with vascular invasion) according to the 6th edition of the AJCC Cancer Staging Manual [4].

At follow-up 19 months after surgery, no local recurrence or metachronous HCC was observed. 22 months after surgery, the des-gamma-carboxy prothrombin level was $1,157 \mathrm{mAU} / \mathrm{ml}$, but no recurrent $\mathrm{HCC}$ was detected from the cervix to the pelvis using contrast-enhanced CT, bone scintigraphy and upper gastrointestinal endoscopy. Physical examination revealed no palpable neck nodule and the patient had no symptoms. Whole body screening was performed at 22 months after surgery using FDG-PET/CT. Screening revealed a hypodense tumor in the left lobe of the thyroid exhibiting high fluorine-18 fluorodeoxyglucose (FDG) uptake with a maximum standardized uptake value (SUV $\max$ ) of 5.2. Metastasis from HCC was suspected (ig. 2a $a$ c). 
The contrast-enhanced cervical CT performed 22 months after surgery had actually revealed a slight swelling of the left thyroid, but this in itself was not meaningful (fig. 2b). A solitary tumor with the profile of a hypoechoic heterogeneous nodule was detected in the left thyroid using ultrasonography. There was no metastatic focus except for the thyroid metastasis. Fine needle aspiration of the thyroid nodule was performed for diagnosis. Subsequent cytology revealed atypical epithelial cells with a granular abundant cytoplasm, hyperchromatic irregular nuclei and marked prominent nucleoli. The diagnosis made from the cytology was solitary metastatic HCC in the left thyroid.

26 months after the original hepatic lobectomy the patient underwent thyroidectomy of the left lobe, with regional lymph node dissection, since the regional lymph node was slightly swollen and lymph node metastasis from HCC was suspected, which is very rare (fig. $3 \mathrm{a})$. Microscopic analysis revealed that adipose and muscular tissue in the left lobe had been invaded by carcinoma cells and that vascular invasion was also prominent. Poorly differentiated HCC was arranged in trabecular and nest patterns (fig. 3b). The surgical margin was infiltrated by the carcinoma cells. All the lymph nodes submitted for examination were found to be free of carcinoma cells. Two months after the thyroidectomy local recurrence of HCC was detected in the remnant of the thyroid and the tumor embolus in the left brachiocephalic vein, using contrast-enhanced cervical CT. To date, 13 months have passed since the solitary thyroid metastasis was diagnosed. The patient has undergone radiation therapy but not surgery for the local recurrence and the tumor embolus, in accordance with the patient's and family's wish to avoid an operation. Examination of the whole body with modalities that have included FDG-PET/CT has so far revealed no distant metastasis, with the exception of the local recurrence of HCC in the thyroid. No intrahepatic metastases have been found.

\section{Discussion}

The present report is the first on clinically diagnosed, asymptomatic solitary thyroid metastasis from HCC. The diagnosis of thyroid metastasis proved very difficult due to the lack of symptoms and the fact that the solitary mass could not be detected clearly using contrast-enhanced CT. The only clue was a rise in tumor marker level, and even with contrast-enhanced CT it was difficult to confirm a diagnosis of thyroid metastasis. Due to the ability of FDG-PET/CT to detect aspects of glucose metabolism, the modality was very useful for discriminating between malignancy and inflammation. Another great merit of FDG-PET/CT is its ability to scan the whole body in a single session. We were able to perform the thyroidectomy of the left lobe, with regional lymph node dissection, much earlier than would have otherwise been possible had it not been for FDG-PET/CT.

Previous reports have indicated that metastases from HCC have been detected at autopsy and in surgical specimens from lung (18.1-49.2\%), lymph nodes (26.5-41.7\%), bones $(4.2-16.3 \%)$ and adrenal glands $(8.4-15.4 \%)[6,7]$. With regard to thyroid metastases, the primary tumor type has been reported to be breast cancer $(28 \%)$, followed by lymphoma (17\%), lung cancer (14\%) and head and neck cancer $(13 \%)[8,9]$. The incidence of thyroid metastases from HCC discovered at autopsy has been reported to vary from 0.8 to $12 \%[9,10]$. Prior to our case, only 4 cases of thyroid metastases from HCC have been diagnosed. These cases were synchronous multiple metastases from HCC that included the thyroid (table 1) [10-12]. Due to clear symptoms and a palpable cervical mass, the antemortem diagnosis of thyroid metastasis from HCC was very easy in these four cases.

FDG-PET/CT is a useful tool for the detection of metastatic liver tumors due to its high sensitivity. However, in the detection of HCC metastases in the liver, especially well-differentiated HCC metastases, it has been reported that the sensitivity of FDG-PET/CT is considerably lower $[13,14]$. Accumulation of FDG in tumors reflects the activity of enzymes involved in glucose metabolism [13]. The activity of glucose-6phosphatase, which converts FDG-6-P to FDG, is usually high in normal liver. In addition, this enzyme activity in well-differentiated HCC cells results in FDG metabolism 
at a similar rate to that in normal liver tissue. In contrast, this enzyme activity is much lower in undifferentiated HCC cells $[13,15]$. Therefore, on this basis, it is thought that well-differentiated HCC usually shows low SUV and that poorly-differentiated HCC tends to show relatively high SUV.

To date, no detailed reports have been published concerning the diagnosis of thyroid metastasis by FDG-PET/CT. However, FDG-PET/CT is considered to be useful for the discrimination of benign tumors and metastatic tumors, as well as changes in the degree of differentiation [15]. This is a major advantage in the use of FDG-PET/CT for tumor detection. Therefore, FDG-PET/CT is recommended for HCC patients when screening for extrahepatic metastases or other malignancies, prior to surgical resection or liver transplantation, and for the monitoring of extrahepatic metastases after chemotherapy or radiation therapy.

In conclusion, our study indicated that solitary thyroid metastasis from HCC can occur even after hepatectomy. A strategy that uses FDG-PET/CT together with contrast-enhanced CT for postoperative whole body screening proved very effective. This approach would benefit future patients that may be at risk of distant metastasis, where there are no symptoms except a rise in the tumor marker level, as was found to be the case in our patient.

Table 1. Characteristics of patients with thyroid metastases from HCC

\begin{tabular}{|c|c|c|c|c|c|c|c|c|c|}
\hline No. & Age & Sex & $\begin{array}{l}\text { FNA } \\
\text { cytology }\end{array}$ & $\begin{array}{l}\text { Other metastatic } \\
\text { sites }\end{array}$ & $\begin{array}{l}\text { Time to } \\
\text { metastasis }\end{array}$ & $\begin{array}{l}\text { Differentiation } \\
\text { of HCC }\end{array}$ & Treatment & Survival & Ref. \\
\hline 1 & 41 & M & $\mathrm{HCC}$ & $\begin{array}{l}\text { lung, liver, } \\
\text { retroperitoneal } \\
\text { lymph node }\end{array}$ & 5 months & NA & NA & 1 month & 11 \\
\hline 2 & 54 & M & cancer & $\begin{array}{l}\text { multiple } \\
\text { intrahepatic }\end{array}$ & 7 months & poor & BSC & 8 months & 12 \\
\hline 3 & 67 & M & $\begin{array}{l}\text { adeno- } \\
\text { carcinoma }\end{array}$ & lung & simultaneous & NA & NA & 1 month & 11 \\
\hline 4 & 78 & $M$ & ND & $\begin{array}{l}\text { bones (shoulder } \\
\text { and rib) }\end{array}$ & simultaneous & well & BSC & 7 months & 10 \\
\hline 5 & 73 & $\mathrm{M}$ & HCC & none & 22 months & $\begin{array}{l}\text { moderate } \\
\text { to poor }\end{array}$ & $\begin{array}{l}\text { thyroid- } \\
\text { ectomy }\end{array}$ & $\begin{array}{l}12 \text { months } \\
\text { (survival) }\end{array}$ & $\begin{array}{l}\text { present } \\
\text { case }\end{array}$ \\
\hline
\end{tabular}

FNA = Fine-needle aspiration; $\mathrm{HCC}=$ hepatocellular carcinoma; $\mathrm{BSC}=$ best supportive care; $\mathrm{NA}=$ not available; $\mathrm{ND}=$ not done. 


\begin{tabular}{r|l|l|l} 
Case Reports in & $\begin{array}{l}\text { Case Rep Gastroenterol 2010;4:279-285 } \\
\text { D0I: 10.1159/000318858 }\end{array}$ & Published online: August 2, 2010 & $\begin{array}{l}\text { O 2010 S. Karger AG, Basel } \\
\text { ISSN 1662-0631 } \\
\text { www.karger.com/crg }\end{array}$ \\
\hline
\end{tabular}

Fig. 1. Macroscopic (a) and histopathological findings (b) from analysis of the primary HCC. The cut surface of the tumor showed a well-defined, tan-white and firm tumor measuring $5.3 \times 5.1 \times 4.3 \mathrm{~cm}$. The tumor exhibited moderately- to poorly-differentiated HCC growing in trabecular and compact patterns, with a grade of $2-3$. Invasion of the distant portal vein and distal vein was evident. Hematoxylin and eosin $\times 100$.

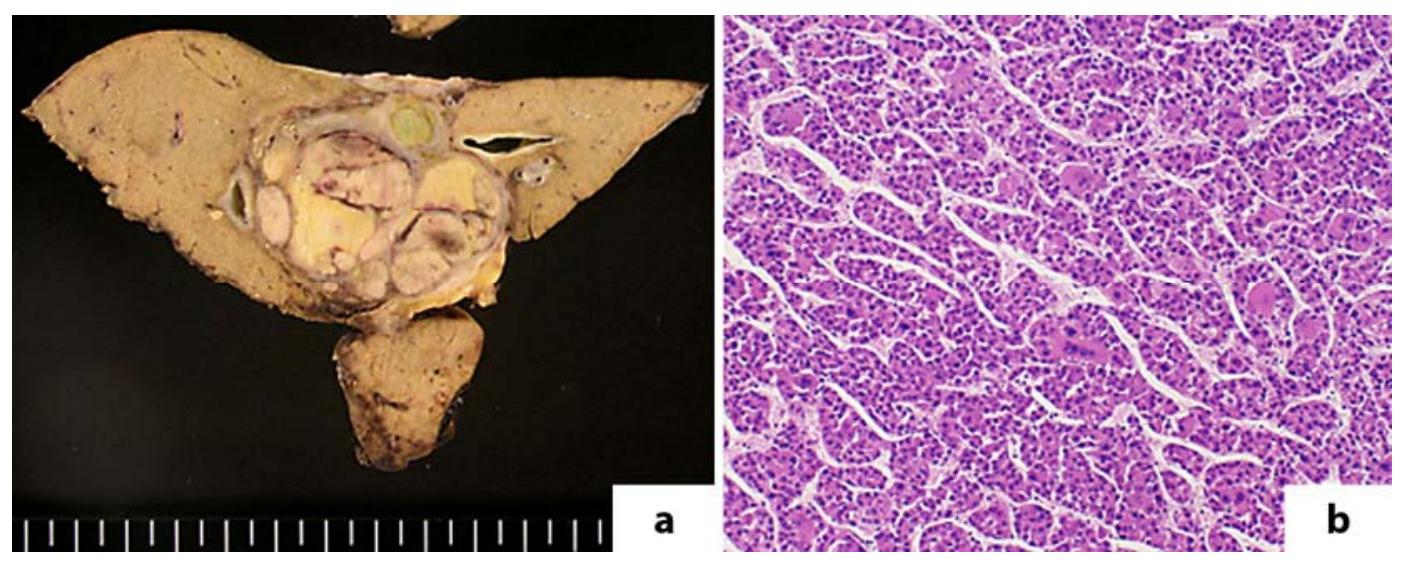

Fig. 2. a Whole body FDG-PET/CT showing a solitary highly metabolic focus in the left side of the neck (arrow). b Contrast-enhanced cervical CT showing slight swelling of the left thyroid (arrow).
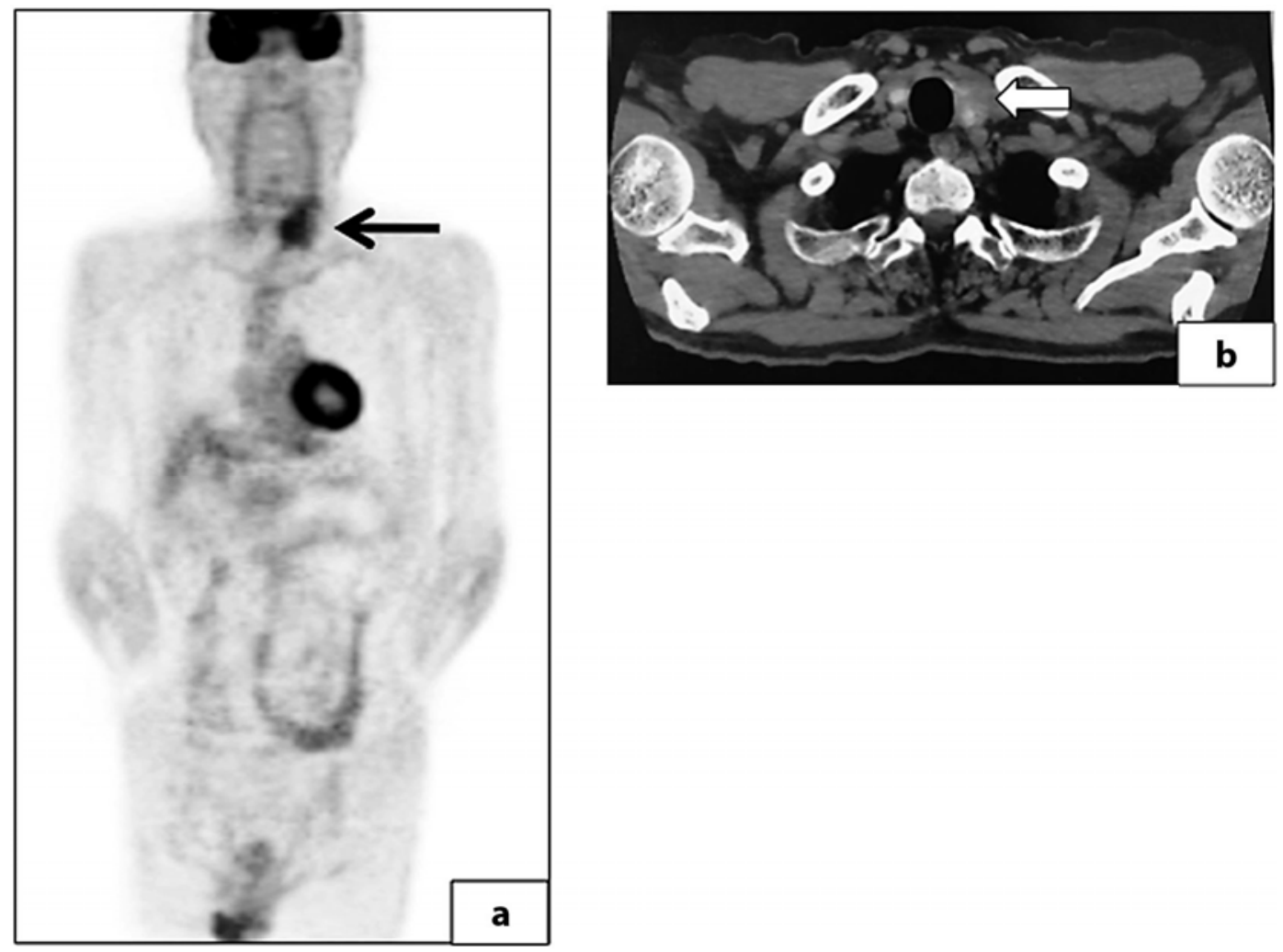


\begin{tabular}{r|l|l|l} 
Case Reports in & $\begin{array}{l}\text { Case Rep Gastroenterol 2010;4:279-285 } \\
\text { D0I: 10.1159/000318858 }\end{array}$ & Published online: August 2, 2010 & $\begin{array}{l}\text { O 2010 S. Karger AG, Basel } \\
\text { ISSN 1662-0631 } \\
\text { www.karger.com/crg }\end{array}$ \\
\hline
\end{tabular}

Fig. 3. Macroscopic (a) and histopathological findings (b) related to the thyroid metastasis. The cut surface of the tumor exhibited a well-defined, tan-white and firm tumor measuring $5.3 \times 4.3 \mathrm{~cm}$. The tumor showed poorly-differentiated HCC arranged in trabecular and nest patterns. The carcinoma cells could be seen invading the vascular and muscular tissue. Hematoxylin and eosin $\times 100$.
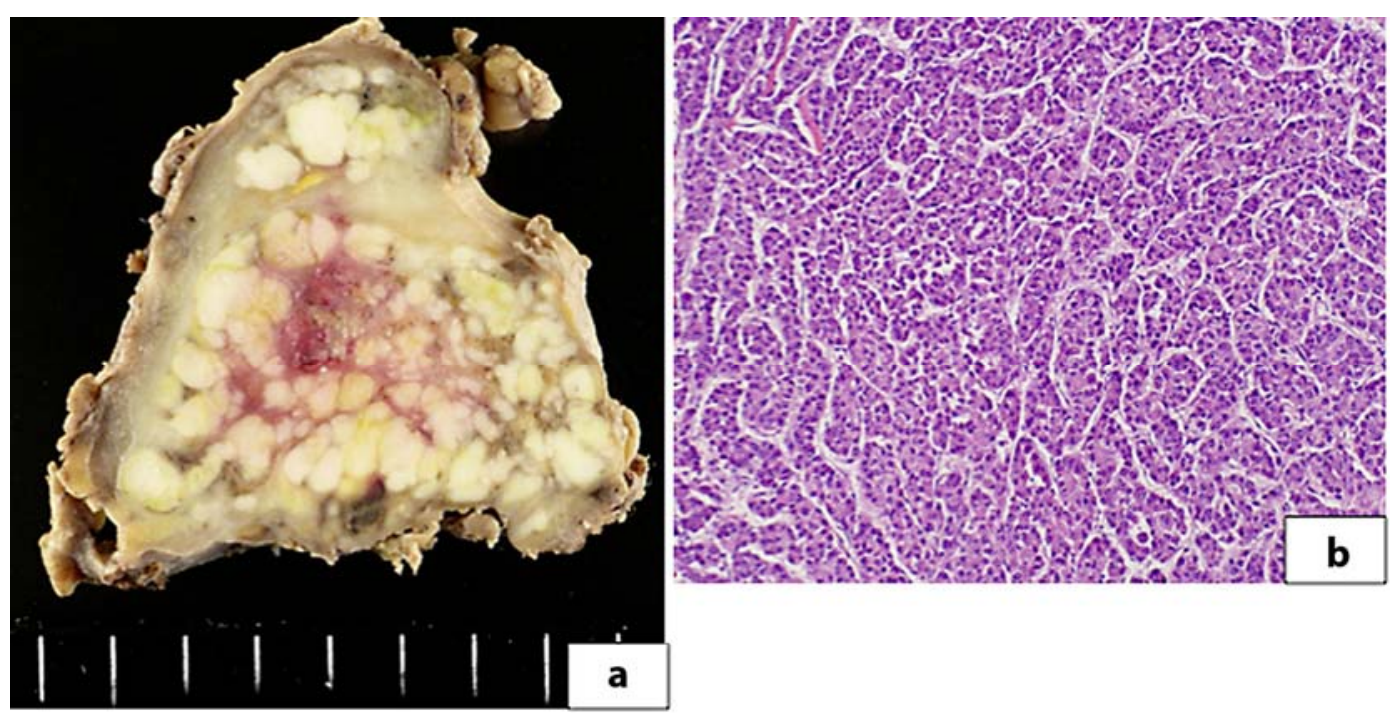


\section{References}

1 Mazzaferro V, Regalia E, Doci R, Andreola S, Pulvirenti A, Bozzetti F, Montalto F, Ammatuna M, Morabito A, Gennari L: Liver transplantation for the treatment of small hepatocellular carcinomas in patients with cirrhosis. N Engl J Med 1996;334:693-699.

-2 Llovet JM, Real MI, Montana X, Planas R, Coll S, Aponte J, Ayuso C, Sala M, Muchart J, Sola R, Rodes J, Bruix J; Barcelona Liver Cancer Group: Arterial embolisation or chemoembolisation versus symptomatic treatment in patients with unresectable hepatocellular carcinoma: a randomized controlled trial. Lancet 2002;359:1734-1739.

-3 El Serag HB, Mason AC: Rising incidence of hepatocellular carcinoma in the United States. N Engl J Med 1999;340:745-750.

4 The AJCC Comparison Guide: Fifth Versus Sixth Edition. http://www.cancerstage.org/products/ajccguide.pdf.

-5 Zhang Z, Liu Q, He J, Yang J, Yang G, Wu M: The effect of preoperative transcatheter hepatic arterial chemoembolization on disease-free survival after hepatectomy for hepatocellular carcinoma. Cancer 2000;89:2606-2612.

-6 Yuki K, Hirohashi S, Sakamoto M, Kanai T, Shimosato Y: Growth and spread of hepatocellular carcinoma. A review of 240 consecutive autopsy cases. Cancer 1990;66:2174-2179.

-7 Ho J, Wu PC, Kung TM: An autopsy study of hepatocellular carcinoma in Hong Kong. Pathology 1981;13:409-416.

8 Wychulis AR, Beahrs OH, Woolner LB: Metastasis of carcinoma to the thyroid gland. Ann Surg 1964;160:169-177.

9 Nakhjavani MK, Gharib H, Goellner JR, van Heerden JA: Metastasis to the thyroid gland: A report of 43 cases. Cancer 1997;79:574-578.

10 Masuda T, Fukuya T, Ono M, Mitsuyama S, Toyoshima S: Thyroid metastasis from hepatocellular carcinoma as an initial presentation: a case report. Radiat Med 2001;19:43-46.

-11 Tsou PL, Chang TC: Ultrasonographic and cytologic findings of metastatic cancer in the thyroid gland. J Formos Med Assoc 2001;100:106-112.

12 Liang HH, Wu CH, Tam KW, Chai CY, Lin SE, Chen SC: Thyroid metastasis in a patient with hepatocellular carcinoma: case report and review of literature. World J Surg Oncol 2007;5:144.

13 Okazumi S, Isono K, Enomoto K, Kikuchi T, Ozaki M, Yamamoto H, Hayashi H, Asano T, Ryu M: Evaluation of liver tumors using fluorine-18-fluorodeoxyglucose PET: characterization of tumor and assessment of effect of treatment. J Nucl Med 1992;33:333-339.

14 Trojan J, Schroeder O, Raedle J, Baum RP, Herrmann G, Jacobi V, Zeuzem S: Fluorine-18 FDG positron emission tomography for imaging of hepatocellular carcinoma. Am J Gastroenterol 1999;94:3314-3319.

15 Torizuka T, Tamaki N, Inokuma T, Magata Y, Sasayama S, Yonekura Y, Tanaka A, Yamaoka Y, Yamamoto K, Konishi J: In vivo assessment of glucose metabolism in hepatocellular carcinoma with FDG-PET. J Nucl Med 1995;36:1811-1817. 